\title{
2
}

\section{MUSEOGRAPHY AND \\ PERFORMATIVITY: PERFORMANCE DESIGN FOR IMPOSSIBLE OBJECTS AND IMMERSIVE DISPLAYS}

\author{
Rodrigo Tisi Paredes
}

The incorporation of digital technologies along with a variety of immersive, more broadly accessible presentational forms in exhibition design are crucial in the updates that several museums and cultural institutions are adopting. Chile is not far from this reality. This text will elaborate on technological experiments that this author explored through an experimental design approach that employs both forms of art (experiential data) and forms of science (objective data), and the capacity of performance ${ }^{1}$ to give meaning and life to non-physical things, captured through the term 'performance design.' In the following pages, I discuss the experimental design of two exhibitions developed with $M_{E S S^{3}}$ and a team from Santiago of Chile's Museo Chileno de Arte Precolombino or MCHAP (PreColumbian Art Museum). ${ }^{4}$ The challenge of these experiments was first to demonstrate that immersive exhibition spaces can evoke presences that are of value for culture and the transmission of heritage, second, to design, via the notion of impossible objects, displays that would make present (for viewers) things that could not be transported to the rooms of the museum, and third, to work on a collaborative process of creation with several professionals that the museum was not used to. Using new digital forms that are fast becoming part of mainstream culture allowed me to conceive fresher, more exploratory and more immersive, experience-oriented exhibitions to create new forms of display, using panoramic photography and video in large formats, animated video projections, droneenabled videos, interactive 3D animations, mapping projections, recorded ethnographic testimonies, landscape sounds, ancient drawings, diagrams and texts. All these communicational elements served as interfaces that allowed visitors to decode and interact with the content presented, but also to evoke objects that were absent from the rooms of the museum, either because they were lost in the past or located in an inaccessible desert. 
Opportunities like these give designers a space to explore their design processes and methodologies and find new means of participation and interaction. Because the technology is becoming more and more user-friendly, digital platforms help to connect diverse peoples and consequently contribute to shape new social perceptions that lead to a stronger understanding of collective experience.

Performance plays a fundamental role in giving form to different acts, and therefore to culture by shaping different spatial-temporal situations that ultimately become moments of experience. Performance can also help to shape the transmission of knowledge within different cultural contexts and for different groups of people. For the purposes of exhibition design, this understanding of performance helped me to speculate on the impact that these design experiments could have. ${ }^{5}$ This turns out to be significant concerning impossible objects, ${ }^{6}$ because it allowed me to construct complex illusional displays, informed by the combination of concrete facts and more subjective perceptions of reality, to evoke absent (archeological) objects - as well as places, peoples and customs outside the museum. Such performative objects employ common forms/languages/codes/values and are built with material and immaterial fragments and audio-visual effects. They allow participatory, experiential learning and demonstrate that immersive spaces can recall presences that are of symbolic value for the preservation and renewal of cultural heritage.

\section{Exhibition spaces, to travel}

In an increasingly consumerist world, one could say that exhibition spaces within museums are significant because they give form to specific contents intended for broad audiences that are relevant for society. These groups are of different classes and of different ethnicities with different cultural backgrounds, and more importantly, they are all mass media inflected. Questions of sense, meaning, context and illusions are part of the equation museums must solve to perform. Audiences can be captivated, just like their perception can be manipulated (Debord, 2000). Exhibitions are fundamentally theatrical and participatory for they are how museums act to transmit the knowledge they create. As spaces for engaging and manipulating audiences in experiences of knowledge, exhibitions are set somewhere in between the black-boxes of theatres and the white cubes of gallery spaces. The white cube is a transitional device that attempts to bleach out the past and at the same time controls the future by appealing to supposedly transcendental modes of presence and power. The problem with these transcendental principles is that, by definition, they speak of another world, not the one we live in (O’Doherty, 1986). Furthermore, in discussing theatrical spaces, Peter Brook elaborates on black boxes to problematise the idea of empty spaces, and argues that there is no such thing as an empty space as they are always read or framed within a context that comes with the cultural background and viewer's mind (Brook, 2008). These black spaces can be framed on different contexts and function more like spaces for travel, for 'visiting' parallel spatial situations that appear because 
perception is manipulated (Foucault, 1967). ${ }^{7}$ In this sense, performance design could play a fundamental role in museums, helping to create this kind of grey box space of imaginative travel. Relevant to this point, Barbara Kirshenblatt-Gimblett (1998) describes two common display approaches: in-situ displays, which are based on the use of dioramas, period rooms and other mimetic re-creations of settings, and in-context displays, which include particular objects arranged according to conceptual frames of reference as a taxonomy, evolutionary sequence, historical development, with a set of formal relationships. These two modes of display differ in their approach to the performativity of objects displayed and the nature of their mise-en-scène. In-context displays depend on the 'drama' offered by the artefact. Here, objects become the actors, and knowledge orchestrates them in environmental settings. They privilege experience and tend to thematise rather than set their subject forth. In-context display build an intellectual framework for the reading of the pieces displayed, most of the time concerning spatial situations and its peoples. The design experiments discussed here are placed on a middle point between in-situ and in-context displays, because they contribute to constructing an ambience where these objects exist (existed or could exist), inviting the audience to imaginatively travel and contextualise display materials within particular narratives of meaning and value.

\section{Presences and absences, to display}

Just like people display objects to communicate to themselves and others, museums display objects of the past to present and re-present stories that are of cultural value to society. Objects are relevant because they contribute to the shaping of memories but also because they offer certain meanings or values. ${ }^{8}$ Depending on the context in which they are presented, these objects allow for the 'collaborative' construction of new (symbolic) meanings with the people who consume or appreciate them. From a sociological standpoint, John Urry argues that such 'travelling' objects that are chosen for display can be problematic, because their value changes with different audiences, as readings of them depend on the situational context. Yet objects are significant, because they can help articulate cohesion within different groups of society as they represent collective beliefs which are relevant to describing heritage and belongings (Urry, 1995). When objects from ancient cultures are displayed and appreciated, they enable and project new meanings and values for society. This highlights questions about the display itself, the performativity propelled by the objects presented and, more importantly, the political economies around such cultural valorisation. ${ }^{9}$ Given that the exhibition of objects has the potential to build arguments, construct new readings of reality and raise questions about present and future times, a performative approach to design matters. It enables an understanding of cultural transmission as enacted by objects and peoples (events), formal intellectual frameworks and audiences' situations, which are all involved in a 'collaborative' performance with the goal of constructing meaning via memorable temporal experiences 
(Tisi, 2011). From this perspective, performance design searches for the construction of impossible objects, i.e. objects that cannot be presented physically but can be made present to audiences via various material forms and communication technologies, whether mechanical, electronic or digital. With their particular backgrounds, audiences play a fundamental role in the perception of these impossible objects, as they need to 'travel' to make them perform.

\section{Museographer, to integrate}

The driving question of my design experiments was this: How can an exhibition effectively present the heritage of an ancient culture and associated issues without having these historical objects present? This observation pushed me, as the museographer, to think about collaboration. I decided to shape a performance of participation throughout the design process, which formed not only the exhibitions but also the phases carried out to execute them. ${ }^{10}$ The designers worked on the artistic dimensions of the exhibition and the museum specialists worked on the scientific/technical aspects of the content. We engaged in negotiations to develop the narrative and the spatial progression that unfolded the stories. As an outsider called in to work closely with a museum team (that included the director of the museum, the chief curator, other curators, a videographer, a conservationist, a graphic designer and a communication specialist, among others), I could take some risks that the internal team could not, for instance conceiving an exhibition without objects. Everyone on the team was open to exploring the performative approaches; indeed, they were intrigued - and willing to experiment with the capacities that performance design and digital technologies offered throughout the process. This willingness on the part of the museum team was crucial and resulted in a rich process, technologically and theoretically complex displays and a positive, collectively realised outcome.

We did, however, face difficult moments and debate throughout the development process. Discussions were mainly focussed on economic concerns and the amount of technology the museography should have. A back-and-forth methodology of iteration (typical of any design process) invited members of the team to participate and speculate on our meetings about what was possible and what was not, thereby addressing issues and finding new possibilities, but also making the design process slower. While I was cautious about when to open a space for deliberation and when to assert my initial design ideas, this collaboration nourished the result in unexpected ways. The process included a variety of evaluations done with different materials and prototypes, meant to test experiences and build fragments of the elements to be displayed. The exhibition experiments served to validate both my performative approach (that was not only looking at the result but also the process) and further collaboration with the curator, allowing the team to re-think the proposed narratives behind each of the exhibitions. Ultimately, the collaborative process contributed to the creation of new communicational forms, including parallel campaigns based on social networks. ${ }^{11}$ Together, the exhibitions 
and ancillary campaigns helped to develop an extension of the museum's presence beyond the limits of its building.

\section{ROSTROS del Norte Grande (FACES of the Great North) ${ }^{12}$}

The design of the exhibition ROSTROS del Norte Grande, which opened in 2016 at Sala Fundación Minera Escondida (Antofagasta), was based on different illustrations gathered over several decades. Most of these drawings were realised by illustrator José Pérez de Arce and were meant to present the everyday life of Atacameños, who lived in northern Chile several hundred years ago. ${ }^{13}$ The museum opened the exhibition in northern Chile, to display its contents first to those who live in the communities of that area. The second presentation was in a small exhibition space located in San Pedro de Atacama and served to pay respect to living descendants of native Atacameños. After these successful presentations, the exhibition moved to the Santiago museum.

The entry area of the exhibition space displayed the printed drawings of Perez de Arce. The following (main) space presented six stories via digitally animated figures, which were based on ethnographic videos, and different interviews conducted to living Atacameños. The museography considered an immersive display landscape, of six vertical screens, shaped like totems, and placed on a circular form, in a semi-dark space, enlivened with ambient natural sounds typical of the desert. The totem/screens displayed video animations combining faces from the original archaeological drawings and those of living descendants. On a confined space at the back, an intriguing video animation that looked like a hologram dancing figure was displayed by vertical projections. All seven images floating in the darkness of the room narrated stories, like the spoken memories of relatives as ghosts of a past communicating an intangible heritage. All elements were assembled to stimulate audio-visual senses of viewers, they told stories in an enigmatic temporal ambience, bringing past and present together (see Figure 2.1).

Perez de Arce's illustrations are important because they enact an effort to portray the faces of our pre-Columbian ancestors. Based on archaeological excavations, the drawings depict the people who lived in the Atacama Desert, their everyday life activities, and the objects they used. These drawings present ways in which these ancient peoples lived and interacted, allowing us to see and imagine their lives. The drawings teach us about ancient clothing, crafts, cookware, weapons and other objects that people used. The performance design team recreated these static evocations of past lives in a more dynamic form to establish a dialogue with the audience. Without present bodies, the animations of people, practices and environments constituted the impossible objects and matter of the display, like absent presences.

The museography provided a performative experience, inviting visitors to navigate through moments of the past and to raise questions of the present (and the future) of Atacameños. The animated drawings in the immersive space lead the audience to think about possible reformulations not only of some kind of 


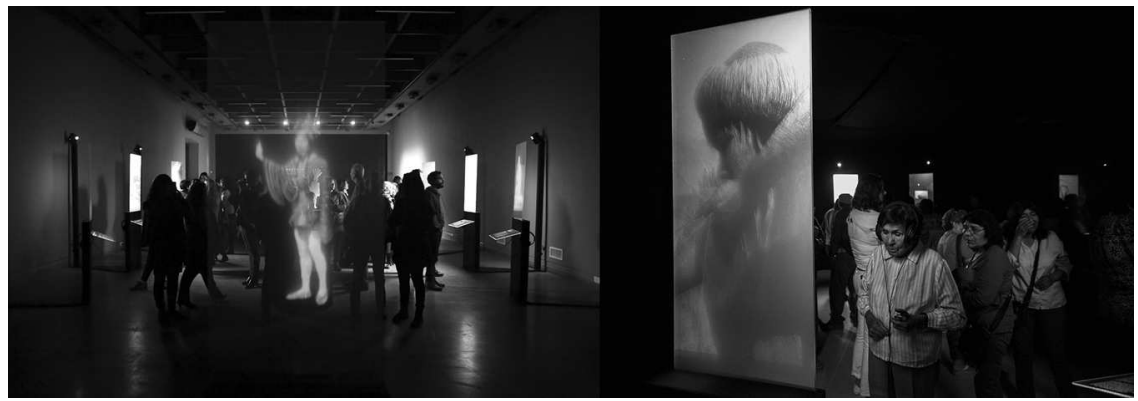

FIGURE 2.1 Left: immersive space displaying video-holographic forms of indigenous people of the past interacting with people living in the present. Right: local descendant listening to local stories about her own ancestors illustrated by archaeological drawings. Here, design elements stage an encounter between past and present, provoking questions of a 'dead' past versus living heritage. Photograph credits: Simón Gallardo (left), Rodrigo Tisi (right).

abstracted cultural heritage but also the inherited social problems, and problematic practices, that exist in the north and with us today. More broadly speaking, the museography shaped something relevant because it raised questions about local customs, survival practices, ancestors, traditions and heritage that root aspects of Chilean culture.

The impossible objects thus created evoke long-ago individuals and bring awareness to the past alive in the present. The aim was to narrate information relevant to a local discussion of ancient traditions and original towns - and to call local attention about local issues related to water and land production. The exhibition presented in the north of the country was meant to reach an audience mainly composed of students and their families (local descendants) and also foreign tourists. The exhibition explores contingent stories about living people, endangered agriculture, local barters and the minimisation of water resources. For Atacameños culture, water is a fundamental survival resource, and water issues are a pressing concern, as this area is now facing water scarcity due to climate change.

To articulate these concerns in a compelling and direct way, the exhibition employed on-site ethnographic research. The team shot video and recorded ambient sounds of the desert (water, animals and plants), as they are seen and heard today. These audio-visual pieces became valuable fragments of site documentation, evoking current experiences of the living descendants. They helped viewers feel the site, the past that is alive in the present moment, not least in the bodies and experiences of local descendants. ${ }^{14}$ The sounds and images of the desert help animate the impossible objects - the totems - enriching thereby the theatrical, in-situ aspects of the display. They serve as well to construct the in-context aspects, expanding the narrative to include the geographical site and its environmental issues. The museum experience, then, is like neither the black box nor the white cube, but somewhere in between, a hybrid grey, completed by the subjective readings of the visitors. 
Because social practices are 'inherited' - repeated and revised as ways to deal with environmental, economic, socio-cultural concerns, the value of these impossible objects is better understood if we consider Richard Schechner's notion of restored behaviour. ${ }^{15}$ This lens plays a double role here. First, it helps us see reenactments of historical objects as preserving and renewing meaning, and secondly, it helps us see how these same re-imagined objects raise awareness of different (regional) situations. The display of ROSTROS then becomes a device for storytelling based on evidence of the past intertwined with the present, a 'stage tour' of reality. ${ }^{16}$ This experimental approach to the archives (and research drawings) construct the narrative of a particular past-present, stimulating possible readings by the viewer and raising questions about the lives of these families in the future (the descendants that are honoured in the animated videos). In 2017, ROSTROS del Norte Grande was presented in Santiago and recognised as the best museography of the 6th Design Biennial of Chile. It seems that the cultural bridges that this performance design established between the ancient Atacameños and their living descendants made the difference.

\section{TAIRA: el amanecer del arte en Atacama ${ }^{17}$}

After completing ROSTROS del Norte Grande, I was called again. In this occasion, I was asked to devise a way to present the rock-art of TAIRA's eave (see Figure 2.2). ${ }^{18}$ This was a challenging invitation because the artworks in question are engraved on the rock walls of the Loa river's canyon, in a remote, inaccessible part of the Atacama Desert. TAIRA's rock-art can be seen, to use current-day terms, as site-specific environmental art-work. ${ }^{19}$ The engravings cannot be understood as isolated 'art objects,' as they are connected to local beliefs and natural life cycles of the place (Berenguer, 2017). Neither the artwork nor the natural elements intrinsic to it - intense blue sky, volcanos, canyons, fresh water springs, dry desert, bright stars, strong winds and animals, like llamas and guanacos - can be transported to a museum space. ${ }^{20}$

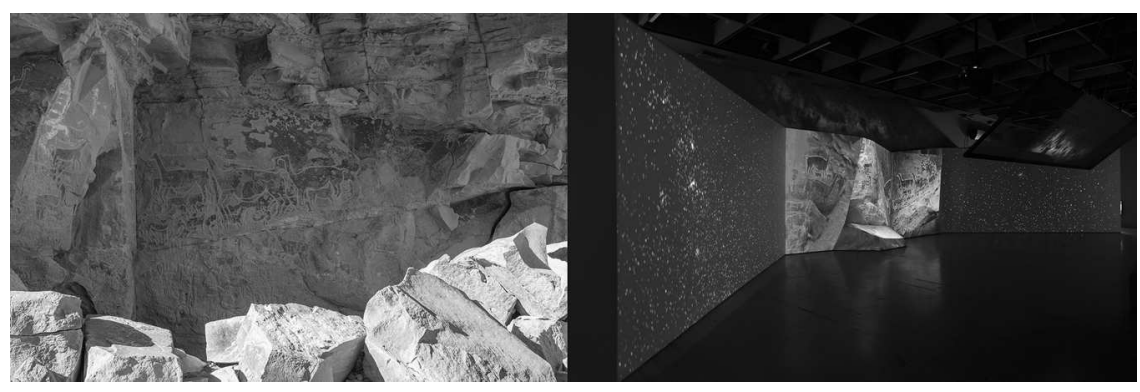

FIGURE 2.2 Left: TAIRA's eave: main triangular panel of the found rock art. Right: TAIRA's eave installation, a multimedia immersive wall animated with mapping at the MCHAP in Santiago. Photograph credits: Rodrigo Tisi (left) and Pablo Blanco (right). 


\section{Rodrigo Tisi Paredes}

For this round, the museography challenge was to re-create the engravings and the natural elements that co-exist on site. Unlike the previous exhibition, where the work was based on illustrations, the challenge here was to find ways to represent and present original archaeological objects. This exhibition was mainly focused on the wall of rock art but also included certain archaeological objects, symbolic to the customs and beliefs of TAIRA's community. The design process ended up producing a site-specific-like art-gallery-wall designed for the space of the museum, which acted as a panoramic, immersive space/wall, emulating natural site conditions and simulating the experience of an on-site visit. Because the rockart is neither well-known nor well-preserved, the museum's goals were to present the role that the eave has for the local community, highlight its value at a national and international level, and recognise it as a unique heritage site in the middle of the Atacama Desert.

The exhibition TAIRA: el amanecer del arte en Atacama, ${ }^{21}$ was meant to trigger a memorable experience for museum visitors and, rather than serving only as touristic cultural consumption, respectfully commemorate rituals of local ancestral values to its own community. Since much of the rock art of TAIRA reveals a deep concern for the fertility of llamas, the researchers argued that the engraved images were linked to their creators' belief about the growth of their herds (Van Kessel, 1976). The creation of these images were ancient ways of obtaining one's wishes: by figuratively representing llamas, these pre-Hispanic herders were able to literally reproduce them. As stated by the museum's researchers, this belief is relevant to the artists' choice of TAIRA eave, rather than other places. More than rock surfaces that were technically suitable for painting or engraving, those rocks were considered 'productive' rocks that, when used to properly re-enact the contract of reciprocity with the gods, would provide abundant harvests of livestock.

The desire to bring the space-time of TAIRA's eave to the museum, to transport visitors on a virtual trip to the north of Chile and explore TAIRA and its context, was challenging. The design team worked together to re-present the rock art as it appears on site, engraved in the stone walls of the valley and to frame it as a record of rituals linking the deities that govern the earth and the sky. The exhibition was meant to develop a concise, linear narrative out of archaeological objects and elucidate historical texts and studies. To provide context and gather material, the team travelled to the site to research site conditions and measure the wall components to be 're-installed' at the museum. We travelled with José Berenguer $^{22}$ and a team including another curator, a video ethnographer, a professional photographer, a drone video-specialist and an architect, to capture all the stories, images and data that we needed to grasp and shape later. This trip allowed us to gather day and night images and footage of environmental elements, which were useful to creating an immersive, experiential display back in the museum. We also gathered time-lapse footage of the rock-art wall that helped us build narratives (between day and night) of the site. As in ROSTROS, interviews were conducted to incorporate the stories of local people belonging to the current TAIRA community. 
The site visit prompted us to consider the use of different media, including video projections, video animations and video mapping, immersive sounds, series of panoramic photographs and a 3D animation made with techniques of photogrammetry. ${ }^{23}$ The immersive audio-visual display was conceived to perform a realistic experience, in 'high definition,' and as close as possible to what existed on site. This was crucial because mediatised information sometimes constructs realities that are stronger than in 'real' life. We used these illusionistic effects to construct something as powerful as what a visit to the eave could be - although certainly different. The display provoked an intensive experience of the sight and sounds of the place while also providing contextual fragments to illuminate the meanings and value of the eave. This strategy made the exhibit more intriguing and dynamic, and framed the experience with intellectual perspectives and challenging questions via an open scripted narrative, provided at times by tours conducted by the museum team and at other times via unguided encounters (allowing for free interpretation and interaction with the display). Visitors thereby benefitted from both educational and experiential approaches.

The material aspects of the project and technological mechanisms used to communicate intangible values were key concerns throughout the design process, as they constituted the dimensions that shaped the performance. The team designed a journey in time and space via an interactive screen allowing visitors to navigate a 3D model of the site, which invited people to 'perform' a flight. The views of the desert site and the perceived panoramas were impossible images; although human eyes cannot fly that northern blue sky, a drone can. The views collected from the eyes of an electronic bird re-created the ecosystem around the rock art, provoking connections between the off-site viewers with the site itself. As stated by researchers, the sky, land, animals and local practices of the descendants are intrinsic to the engravings themselves; therefore, such a virtual tour (from the eyes of an improbable bird) is crucial to visitors' understanding of the art and its site (Sinclaire \& Martinez, 2018).

As in ROSTROS, the museography also constituted an occasion to explore different technological possibilities, devising new forms of communication between the exhibited content and the viewers (of different ages and diverse cultural origins). For this reason, the more universal languages of audio-visual representations were required. The display also considered a $\mathrm{QR}$ code that enabled visitors to download the 3D navigable animation of TAIRA. ${ }^{24}$ The idea was to offer a version that the viewer could take home - a souvenir visualisation of the Loa river and its remote desert canyon. This digital representation extended the space of the exhibition beyond the museum and enabled a new experience of the site, of other spaces, on a context that emphasised the impossible. ${ }^{25}$

But an exhibition cannot be just a form of presentation and representation. It should also be understood in more complex dimensions, with an open, active approach to the public that absorbs the content while engaging with performative dimensions of the exhibition. In this sense, the project not only dealt with the organisation of objects and spatial elements but also used certain theatrical 


\section{Rodrigo Tisi Paredes}

communication and common language resources to act with/on space. ${ }^{26}$ These design challenges lead the team to think of staging different moments throughout the exhibition path, for example, freezing some moments to encourage visitors to take personal photos (selfies) or to listen on headphones to local descendants whispering their stories about local legends. These digitally produced experiences blurred the edges of the museum by the means of different technological platforms. This actively participatory form of exhibition plus its dissemination via different social networks lead to various levels of performativity. The conscious design of all these characteristics constituted an act of performance, since there was implicit communication between certain images of the exhibition and museum visitors. Furthermore, the exhibition images evoked desires to visit the site or to learn more about it. The exhibition built a unique moment which was neither in TAIRA nor in the museum space where the representation of the eave was. Following its success, the local community of TAIRA made efforts to bring the exhibition to a new space for a permanent display near the eave. If this happens, the area will receive more visitors - not only scientists, academics or privileged tourists, but also more conventional people interested in exploring and engaging with the site and its rock art.

\section{Conclusion}

The two experiments represented methodologies of working with collaborative design and technological challenges and became opportunities to explore performance design with respect to process as well as results. In both cases intense deliberation with the MCHAP team shaped and re-shaped design interests. The methodology established weekly meetings with the museum team and weekly meetings with the creative heads of the MESS team. In the first experiment these negotiations lasted for about four months, in the second, for about eight months. The process in each of the experiments influenced the initial curatorial vision, pushed for new ideas to articulate more sharply the content and narratives, and raised questions concerning appreciation of local heritages and lack of adequate preservation. Much research has been done, for instance, in terms of the archaeological findings of the Atacameños culture, but very little has been done to encourage awareness of this culture at a popular level and for younger generations. The design experiments generated consciousness and prompted change, because the exhibitions were installed several times and initiated new processes of establishing heritage awareness.

Because these exhibitions were made for a museum of pre-Columbian art, the design processes and their results pointed to issues of archaeological objects and art in the past. What is art, if we are thinking about it 3,000 years ago? Who were the people that made this art, and for what purposes? The answers that we offered combined deductive scientific findings with the intuitions of a creative process enabled by design practices of iterations. The experiments enabled participatory methodologies of a creative team (designers) and scientific team (museum 
specialists) that integrated a conventional process with a more experimental and provocative approach. This led to unique experiences in the museum space as well as experiences in relation to audience participation (co-creation of heritage). The audiences were composed first, by families of native descendants and second, by tourists and younger generations. The results highlighted new questions about concrete objects and subjective information that can be orchestrated and guided by means of performance. Is it more relevant to see the originals - often lost or not transportable, or to perform an exhibition that will amplify meanings and values via impossible objects? Indeed, the absence of concrete elements for these exhibitions provided opportunities to shape the meanings and values of the original objects more powerfully. The presentation of carefully designed impossible objects allowed audiences to explore and learn in informal ways about things that were not present. They evoked a more slippery heritage - difficult to pin down, yet vitally present among native communities within Chilean culture.

These experiments played an important role for the museum at a time when cultural institutions in Chile are realising that new, more participatory forms of communication are key to re-establishing museums' relevance. The two experiments were strategic because the institution required a new level of performance, after the museum's restoration in 2014. Thus, these exhibitions constituted a timely update at a moment when the museum was deciding to engage a broader audience in new ways. With the use of digital technologies, MCHAP updated its communication formats to display materials in a fresher manner, incorporating more accessible, popular wording related to the aesthetics of contemporary culture. These efforts also sought to revalue local cultures, as well as furthering the museum's goal of developing a relationship with native peoples and their descendants. The two exhibitions thereby performed for this new museum to a broader, more diverse audience, at a historical moment when the institution literally opened its doors.

\section{Notes}

1 Performance can be defined in the 'doing,' in the present and by means of presentation and representation of something, on an effective manner. Schechner (1998) establishes certain parameters to describe when something is performance (doing something) or when something could be understood as performance (something re-presents something else). Something is performance when the audience understands it and receives it as such (because of participation processes). If the audience manages to understand and engage the performance, that reception causes a favourable effect (sometimes memorable). For purposes of this article, that outcome is what should be understood as performance.

2 The notion of performance design first appeared in 1967 in an issue of Progressive Architecture which was focussed on the impact of new technologies on processes of architectural design. In 2008, Hannah and Harslof edited a book on performance design (resulting from a symposium in Rome). This book explores ideas that are more related to events and enactments that are propelled by temporality. Prior to this, I offered a definition for performance design: a creative practice located between the objective 
facts of the sciences and the subjective facts of the arts. Performance design offers a paradigm for designers (Tisi, 2006).

3 MESS is a collaborative platform launched in 2007, in Santiago de Chile. It works between possible and impossible projects. This platform assumes that each project is different and therefore the creative process is different each time and a different team is needed on each occasion. This platform works with artists, designers, architects, engineers, sociologists and other professionals. For more, visit https://www.mess.cl/

4 The Chilean Museum of Pre-Columbian Art is focused on the pre-Hispanic art of native peoples of the Americas. The main exhibition is divided into different cultural areas using the concept of America without borders, to explore different cultures of the American continent through an exceptional collection of pre-Columbian artefacts donated by the institution's founder, Sergio Larrain García-Moreno. The museum opened in 1981 and went through a main restoration completed in 2014. This museum is significant in the cultural circuit of Santiago and has a broad international audience. During a strategic meeting in 2015 , the museum board decided that the museum should connect with native people of indigenous descent. http://www.precolombino.cl/en/ museo/la-institucion/

5 As a paradigm of architecture, performance evaluates the efficiency of its ambitions. This definition of performance, associated to the construction of space, is relevant to my understanding of temporal exhibition design. As ambitious experiments, these designs can explore issues that the permanent condition of traditional architecture does not allow. In other words, performance gives a dimension of speculation to these spatial experiments conducted on the museum space (Ruby, 2010).

6 From a visual (arts) perspective, impossible objects are defined by perspectives created through geometries that trick the eye. These objects are completed in the mind of the viewer after a process of de-codification. Technically, such objects cannot be constructed, as they are presented in a 2D rather than a 3D form, as for example in Marcel Duchamp's Apolinére Enameled from 1916.

7 Michel Foucault (1967) offered the concept of heterotopias to describe worlds within worlds. These worlds can be constructed within institutional spaces and culture. $\mathrm{He}$ established them as parallel spaces, "other spaces". The notion of heterotopia is related to utopia, which also describes certain impossibilities.

8 Kirshenblatt-Gimblett discusses the ethnographic object as something that is made and not only found. Such objects are of value not because they have a certain quality or appearance that might be of interest, but rather because they raise questions of their source and their destination.

9 If we look at the cultural value of these objects, the Thing theory seems to be central for the argumentation of this text as it challenges the limits of the reading and understanding of objects. The Thing theory questions the relation subject-object to discern on the ideological and ideational effects of the material world rather than only the material effects of ideas and ideologies. This formulation searches for something else from the things that are presented around us. They become objects of value when cultures and societies incorporate them. Things become something when they do something, signify something, or represent something, and if they do, then they display certain reciprocity to a subject (one or multiple individuals or one or multiple objects). This thing theory describes a particular subject-object relation that in the case of museums is crucial as it establishes a space to appreciate and understand content but most fundamentally, nowadays, to experience it (Brown, 2004).

10 The two exhibitions were meant for a temporary space at the museum and served to look at issues of our own local culture and its values. The design processes represented new opportunities to explore radical ideas with the use of technology, and to explore the ambition that the museum had, and that since 2014 has been worked out consistently, to reach wider audiences, with temporal exhibition projects that are more ambitious in their forms. 
11 Since the museum started using popular social networks such as Instagram, Facebook, and Twitter, the number of visitors has increased exponentially.

12 The first exhibition of ROSTROS del Norte Grande was in Antofagasta, from September to October 2016. The second one in San Pedro de Atacama, from November 2016 to February 2017. The third one was in Santiago, from June to August 2017. The MESS team that worked on this exhibition was composed by this author that acted as the creative director and the performance designer strategist; Pedro Silva, assistant designer and manager; Simón Gallardo, audiovisual designer; and Antonieta López, graphic designer. See more information online: http://www.precolombino.cl/ exposiciones/exposicion-itinerante/rostros-del-norte-grande/

13 Atacameños are also known as Likan Antai culture. These native people of the north of Chile lived around the Loa River amidst the Atacama Desert. They are part of a larger group of indigenous people that live in the North of Chile and the South of Perú and Bolivia. Their culture can be traced back to $500 \mathrm{AD}$. They were conquered by the Incas and later by Spaniards. Their culture does not represent a geopolitical division between countries as we are used now. Atacameños can be traced back about 2,500 years.

14 During 2016 the director of the Chilean Museum of pre-Columbian Art, Carlos Aldunate, stated in an interview that: 'These pre-Columbian cultures are not a thing of the past, they are a thing that lives in the present, lives in our miscegenation, in our language and customs and, above all, lives in the current pre-Columbian peoples, who are the legitimate descendants of these people, so that's why it's so important to demonstrate this link between past and present.' See https://radio.uchile.cl/2016/11/10/ jose-perez-de-arce-el-ilustrador-de-los-pueblos-precolombinos/

15 Schechner (2002) states that restored behavior is 'me behaving as if I were someone else.' For him, all behavior consists of recombining previously behaved behaviors. This article explores the notion of restored behavior in the world of objects because they also act within a frame of cultural agreements. Objects embody values and meanings that are repeated depending on the context that they are placed.

16 As described by Aldunate (2016), the exhibition '... was like a stage tour. A presentation of the period of the fishermen, the first to start making pottery and basketry. Then there is a period where all this territory was linked to the Tiahuanaco or Tiwanaku culture of Lake Titicaca and finally, there is a time when relations between all these peoples was very important and developed mainly in the markets.' See: https:// precolombino.cl/en/museo/noticias/rostros-del-norte-grande/

17 The first exhibition of TAIRA: el amanecer del arte en Atacama was done in Santiago between November 2017 to May 2018 at Museo Chileno de Arte Precolombino (MCHAP). The second exhibition happened in Antofagasta, between September 2018 and November 2018 at Sala Fundación Minera Escondida. The MESS team that worked on this exhibition was: this author, as creative director and performance designer; Eduardo Perez, assistant designer and manager; Simón Gallardo, audiovisual designer; Marcelo Fica, audiovisual artist in charge of mapping projections; Antonieta López, graphic designer; Diego Sepúlveda, software programmer; Diego Pinochet, drone controller, photogrammetry and software programmer; Manuel Madariaga, illustrator and colorist designer; Piero Mangiamarchi, space constructor; Marcelo Zunino, assistant to technical construction.

18 TAIRA's rock-art is dated about 2,500-3,000 years ago.

19 Site-specific art is art done in close attention to the place where it is installed. Current trends incorporate the idea of environment to associate site-specific interventions to concerns that are related to environmental crises such as climate change. The artwork serves as a tool to see, study and criticise problems of the surroundings in which they are presented.

20 In talking about the local animals, Luisa Huanuco, one of the few persons that remain to TAIRA's community says that 'the purest and cleanest animal is the llama, because that 
one salutes the sun every day. Soon as the sun touches the mountain it shines, and she is there ... mmm, the only animal that salutes the sun, that's the llama. I love that animal very much ... this little animal, if you know how to take advantage of it, provides a lot. But these days there are very few left. They're disappearing too.' Taken from one of the recordings presented in the audio-visual display.

21 For more, see the exhibition catalogue: TAIRA, al amanecer del arte en Atacama. http://www.precolombino.cl/en/exposiciones/exposicion-itinerante/taira-elamanecer-del-arte-en-atacama-2017/

22 José Berenguer has been the author of several contributions about TAIRA's eave. His studies were very influential for many of the design ideas we explored. Berenguer's intellectual contribution has been recognised in Chile and abroad. His work with local Atacameños included in historical studies the contributions of the living community that are descendants of the roots of TAIRA's eave. In the catalogue of the exhibition, Berenguer (2017) expands ideas about heritage, landscape, animal reproduction and rock art of the north of Chile.

23 Photogrammetry determines geometric characteristics of objects using photography. The project used a drone camera to do an exhaustive survey of the hillside and the canyon of the Loa River, allowing it to re-construct the topological characteristics of the site. Using this technology together with special software, an accurate model of TAIRA's eave was built for the spectators. This contribution to the performance design was done by Diego Pinochet, a colleague that also teaches at the Design Lab - UAI in Santiago, Chile.

24 http://www.precolombino.cl/exposiciones/exposicion-itinerante/taira-el-amanecerdel-arte-en-atacama-2017/el-vuelo-del-condor/fotogrametria-del-alero-taira/

25 See ideas of 'experience' proposed by Dernie (2006). What stands out is to explore new ways of approaching material and content, to see, and literally feel, the message. The strategy of experience also relates to the operations that capture the attention of a less scholarly crowd in and out of the exhibition. In this sense, to bring a piece of the exhibition home, is also to bring the experience to a more private world that performs in different ways to different audiences.

26 For architecture, these elements are translated into materiality: light, program, time and other dimensions that involve the physical configuration of a space, whether temporary or permanent. To expand further in these ideas, see Tisi (2008).

\section{Bibliography}

Aldunate, C. (2019). Chile antes de Chile: Los nuevos tiempos del museo Chileno de Arte Precolombino. Chungará, Revista de Antropología Chilena, 51(2), 181-190.

Berenguer, J. (2017). TAIRA: The dawn of art in Atacama. Museo Chileno de Arte Precolombino.

Berenguer, J., \& Martinez, J. L. (1989). Camelids in the Andes: Rock art, environment and myths. In H. Morphy (Ed.), Animals into art (One world archaeology). Unwin Hyman.

Bishop, C. (2006). Introduction: Viewers as producers. In C. Bishop (Ed.), Participation (pp. 10-17). MIT Press.

Brook, P. (2008). The empty space. Penguin.

Brown, B. (2004). Thing theory. In B. Brown (Ed.), Things (pp. 1-22). University of Chicago Press.

Debord, G. (2000). Society of the spectacle. Black \& Red.

Dernie, D. (2006). Exhibition design. Laurence King Publishing.

Foucault, M. (1967). Of other spaces: Utopias and heterotopias. In N. Leach (Ed.), Rethinking architecture: A reader in cultural theory (pp. 330-336). Routledge. 
Hannah, D., \& Harslof, O. (Eds.). (2008). Performance design. Museum Tusculanum Press.

Kirshenblatt-Gimblett, B. (1998). Destination culture: Tourism, museum, and heritage. University of California Press.

Noordegraaf, J. (2004). Strategies of display, museum presentation in nineteenth and twentieth century visual culture. Nai Publishers.

O'Doherty, B. (1986). Inside the white cube: The ideology of the gallery space. University of California Press.

Ruby, A. (2010). Performance. In M. Gausa (Ed.), The Metapolis dictionary for advanced architecture (p. 476). Actar.

Schechner, R. (1985). Between theater \& anthropology. The University of Pennsylvania Press.

Schechner, R. (1998). Performance theory. Routledge.

Schechner, R. (2002). What is performance? In R. Schechner (Ed.), Performance studies: An introduction (pp. 28-51). Routledge.

Sinclaire, C., \& Martinez, P. (Eds.). (2018). La exposición de arte rupestre de TAIRA tras bambalinas: Seis ensayos y un guion. Museo Chileno de Arte Precolombino.

Tisi, R. (2006). Performance design: On the slippery combination of art and science. Arts Fairs International 2(5/6), 12-13.

Tisi, R. (2008). B + S + P + T + PL + M: Six ways to approach architecture through the lens of performance. JAE: Journal of Architecture Education, 61(4), 69-75.

Tisi, R. (2011). Architecture and performance, the construction of display. UMI Dissertation Publishing.

Urry, J. (1995). How societies remember the past. The Sociological Review, 43(1), 45-65.

Van Kessel, J. J. M. M. (1976). La pictografia rupestre como imagen votiva (Un intento de interpretación antropológica). In H. Niemeyer (Ed.), Homenaje al Dr. Gustavo La Paige S. J. (pp. 227-244). Universidad del Norte. 